\title{
Comparison of Treatment Response in Different Types of Achalasia: A Long-Term Study
}

\author{
Seidamir Pasha Tabaeian ${ }^{1,2}$, Amir Anushiravani ${ }^{3}$, Narges Fazlollahi ${ }^{4}$, Hossein Asl Soleimani ${ }^{5}$, \\ Javad Mikaeli ${ }^{6, *}$
}

1. Department of Internal Medicine, School of Medicine, Iran University of Medical Sciences, Tehran, Iran

2. Colorectal Research Center, Iran University of Medical Sciences, Tehran, Iran

3. Assistant professor of medicine, Digestive Diseases Research Institute, Shariati Hospital, Tehran University of Medical Sciences, Tehran, Iran

4. Medical physician, Digestive Diseases Research Institute, Shariati Hospital, Tehran University of Medical Sciences, Tehran, Iran

5. Associate Professor of Medicine, Digestive Diseases Research Institute, Shariati Hospital, Tehran University of Medical Sciences, Tehran, Iran

6. Professor of Medicine, Digestive Diseases Research Institute, Tehran University of Medical Sciences, Shariati Hospital: Karegar Shomali Ave, Tehran, Iran

* Corresponding Author:

Javad Mikaeli, MD

Digestive Diseases Research Institute, Tehran University of Medical Sciences, Shariati Hospital: Karegar Shomali Ave, Tehran, Iran, postal code: 1411713135

Tel: + 982182415000

Fax: + 982182415400

Email: dr.javad.mikaeli@gmail.com

Received: 07 Nov. 2020

Accepted: 10 May 2021
ABSTRACT

\section{BACKGROUND}

Three manometric patterns are seen in high-resolution manometry (HRM). Response to treatment has been reported to be different in these subtypes. We aimed to investigate the frequency and response to treatment in subtypes of achalasia.

\section{METHODS}

306 patients between 15 to 60 years old, naïve to treatment with idiopathic achalasia (IA) were evaluated prospectively in a cohort study for 8 years. The patients were treated with pneumatic balloon dilation (PBD), and evaluated before and one month after PBD with Achalasia Symptom Score (ASS) and timed barium esophagogram (TBE) and then every 6 months with ASS. The primary study outcome was defined as a reduction in ASS (equal to or less than 4) and a reduction greater than $80 \%$ in the volume of barium in TBE at 1 month after PBD compared with baseline values.

\section{RESULTS}

According to HRM, 57 were classified as type I (18.62\%), 223 as type II (72.9\%), and 26 as type III (8.5\%). The mean lower esophageal sphincter (LES) residual pressures before treatment were $34.05 \pm 31.55,32.99 \pm 17.90$, and $37.47 \pm 14.07 \mathrm{mmHg}$ in types I, II, and III, respectively ( $p=0.18$ ).

The mean ASS values before treatment were 12.23, 11.50, and 11.50, for types I, II, and III, respectively $(p=0.29)$. The ASS dropped to 2.50 in type I, 2.40 in type II, and 2.12 in type III at 1 month after treatment $(p=0.83$ ).

Eventually, at the end of follow-up, 24 patients with type I ( $83 \%), 82$ patients with type II $(67 \%)$, and five patients with type III ( $83 \%)$ showed sustained good responses $(p=0.528)$.

\section{CONCLUSION}

Manometric subtypes of achalasia did not have an important role in clinical success in the long term. Achalasia has no definite cure, but with current treatment modalities, palliation of symptoms is possible in over $90 \%$ of patients.

\section{KEYWORDS:}

Achalasia; Esophagus; Cohort; Treatment

Please cite this paper as:

Tabaeian SAP, Anushiravani A, Fazlollahi N, Asl Soleimani H, Mikaeli J. Comparison of Treatment Response in Different Types of Achalasia: A Long-Term Study. Middle East J Dig Dis 2021;13:186-192. doi: 10.34172/mejdd.2021.224 


\section{INTRODUCTION}

Idiopathic Achalasia (IA), a chronic motor disease involving the esophagus, results from damage of inhibitory ganglion cells of the myenteric plexus and imbalance of the excitatory and inhibitory neurons. ${ }^{1-4}$ This causes an increase in the lower esophageal sphincter (LES) pressure with loss of peristalsis and incomplete relaxation of the LES. ${ }^{5,6}$

Diagnosis is based on clinical, radiographic, endoscopic, and manometric findings. ${ }^{7,8}$ Conventional manometry was used in the past, showing two variants of achalasia: "vigorous" and "classic". 9-12 It could not distinguish between "simultaneous contractions" apt to spastic contraction, rapidly spread, and the intraesophageal pressurization between the location of contraction proximally and a downstream obstruction distally. ${ }^{13,14}$ High-resolution manometry (HRM) has solved this problem. ${ }^{15,16}$ HRM collects data from closely spaced pressure sensors and makes esophageal pressure topography plots (EPT). ${ }^{17}$ Three manometric subtypes have been identified based on the residual esophageal wave pattern: type I, minimal contraction of the esophagus; type II, no peristalsis but intermittent periods of compartmentalized esophageal pressurization; and type III, spastic contractions in the distal esophagus. ${ }^{18,19}$

The frequency and response to treatment are different for each subtype. Type II is the most common, and it is treated more successfully with pneumatic balloon dilation (PBD) or laparoscopic Heller myotomy (LHM). ${ }^{18-23}$ Clinical success rates are the same in types I and II, regarding PBD and LHM. Type III responds better to surgery and per-oral endoscopic myotomy (POEM), probably due to a more extensive proximal disruption of the esophageal muscle. ${ }^{18,22}$

In this study, we aimed to assess the frequency and response to treatment in various achalasia subtypes in our referral center in the long term.

\section{MATERIALS AND METHODS}

\section{Patients}

A total of 306 patients with IA were evaluated between October 2011 and August 2019 in Shariati Hospital affiliated to Tehran University of Medical Sciences. The diagnosis was based on a timed barium esophagogram (TBE), an upper endoscopy to exclude pseudo-achalasia, and was confirmed using high-resolution manometry (HRM). A questionnaire for demographic data and symptoms was filled out by the researcher (NF). The patients were classified as having achalasia type 1, 2, or 3 based on these results and were treated using graded gradual pneumatic balloon dilation (PBD) with a 3-cm Rigiflex balloon. They were evaluated with Achalasia Symptom Score (ASS) at 1 month after treatment and then every 6 months. A timed barium esophagogram was done 1 month after PBD. The frequency and response to treatment were evaluated for each subtype.

The patients with an ASS $>4$ and barium retention at 5 minutes underwent PBD again, this time using a 3.5- or 4.0-cm Rigiflex balloon. Those with no response were candidates for combined therapy (redo PBD four weeks after botulinum toxin injection) or surgical Heller's myotomy. Eventually, the patients' symptoms were classified using Vantrappen's scoring system, and the number of PBDs, failures, and remission were compared between different subtypes.

\section{High-Resolution Manometry}

HRM was done by "Solar GI HRM, Medical Measurement Systems (MMS)" with a 22 water perfused catheter. The catheter of the device has P1 - P 22 sensors of which P1 - P2 are positioned in the stomach, P3 - P6 in the LES, and P7-P22 in the esophageal body, upper esophageal sphincter (UES), and the pharynx. These pressure sensors are provided to plot $1 \mathrm{~mm} \mathrm{Hg}$ after thermal correction with MMS software done for improving data analysis. $^{24}$

After a clear liquid diet for 24 hours and an overnight fast, the catheter was passed from the nose to the stomach in the supine position. The patients were instructed to do a series of wet swallows with at least 30 seconds' interval according to this pattern: 10 wet swallows of $5 \mathrm{~mL}$ and 3 water swallows of $1 \mathrm{~mL}, 10 \mathrm{~mL}$, and $20 \mathrm{~mL}$.

The patients were first evaluated for having normal or impaired LES relaxation. Impaired LES relaxation was defined as an average 4 seconds integrated relaxation pressure (IRP) greater than $15 \mathrm{~mm} \mathrm{Hg}{ }^{25}$ Three achalasia subtypes are seen in HRM according to the Chicago classification version 2. Type I (classic) achalasia: mean IRP $\geq 15 \mathrm{mmHg}, 100 \%$ failed peristalsis. Type II achalasia 
(achalasia with esophageal compression): mean IRP $\geq 15$ $\mathrm{mm} \mathrm{Hg}$, no normal peristalsis, pan-esophageal pressurization with $20 \%$ of swallows. Type III (spastic achalasia): IRP $\geq$ $15 \mathrm{mmHg}$, no normal peristalsis, preserved fragments of distal peristalsis, or premature (spastic) contractions with $20 \%$ of swallows. ${ }^{26}$

\section{Achalasia Symptom Score}

We evaluated symptoms using the ASS, similar to our previous studies. ${ }^{27,28}$ The total symptom score was the sum of the scores for five cardinal symptoms of achalasia and the severity of dysphagia. Returning of food material from the esophagus, active in standing or sitting, and passive in supine or lying positions were defined as regurgitation. The highest possible total symptom score is 18 . The ASS was calculated for each patient at the following intervals: pretreatment, 1, 6, and 12 months after PBD, and then every six months.

A good clinical response was defined as a decrease in ASS to 4 or less, while an increase of 2 or more points in the severity of dysphagia after the initial good response was considered as clinical relapse. The poor response was defined as unfulfilled criteria for a good response. Sustained good response was defined as remaining in clinical remission (ASS equal to or less than 4) at the end of the follow-up.

\section{Timed barium esophagogram (TBE)}

All patients underwent TBE as an objective tool to assess esophageal emptying before and 1 month after treatment. In the upright position, $200 \mathrm{~mL}$ of barium sulfate suspension ( $81 \%$ weight/volume) ${ }^{29}$ was swallowed by patients, and radiographs were taken at 1,3 , and 5 minutes after swallowing from the left posterior oblique view. The barium column height, the distance from the most distal part of the esophagus to the most proximal barium level, was measured in centimeters. The volume of retained barium in milliliters $(\mathrm{mL})$ was calculated as follows: (mean radius) ${ }^{2} \times 3.14 \times$ height of the column. These calculations have been used in a similar study. ${ }^{29}$

The difference in the retained barium height and volume at 5 minutes was calculated between the pre- and post-treatment TBEs. We defined a good response as a reduction greater than $80 \%$ from baseline in the volume of barium at 1 month after $\mathrm{PBD}$, and a poor response as unfulfilled criteria for a good TBE response.

\section{Endoscopy}

Endoscopic evaluation was performed for all patients to confirm idiopathic achalasia and to exclude malignancies. Endoscopic findings included dilated esophagus, retained foamy secretion or food particles, some erythema, and irritation of the esophageal mucosa, hypertonic LES that did not open spontaneously but could be passed by the gentle pressure of the endoscope.

\section{Statistical Analysis}

ANOVA was used to compare the mean of variables among the three achalasia subtypes. Independent variables assessed in the logistic regression model were age, sex, achalasia subtype, IRP, and resting and residual LES pressure. Kaplan Meier test was used for assessing the relapse of symptoms.

\section{RESULTS}

306 patients were enrolled in this study, of whom 156 were female, and 150 were male with a mean age of $39.76 \pm 14.27$ years (range:12-78). There was no significant difference in age and sex between the three subgroups $(p=0.593)$. The median duration of follow-up was $6.77 \pm 5.22$ (1-9 years).

\section{HRM findings}

Out of the 306 patients evaluated, 57 were classified as type I (18.62\%), 223 as type II $(72.9 \%)$, and 26 as type III $(8.5 \%)$. The mean LES residual pressures before treatment were $34.05 \pm 31.55,32.99 \pm 17.90$, and 37.47 $\pm 14.07 \mathrm{~mm} \mathrm{Hg}$ in types I, II, and III, respectively ( $p=$ $0.18)$. The mean IRP, contractile front velocity (CFV), and distal contractile integral (DCI) are shown in table 1.

\section{Primary outcome}

The primary study outcome (short-term response) was defined as a reduction in ASS (equal to or less than 4) and a reduction greater than $80 \%$ in the volume of barium in timed barium esophagogram at 1 month after PBD compared with baseline values.

The mean ASS values before treatment were 12.23, 11.50 , and 11.50 , for types I, II, and III, respectively ( $p=$ $0.29)$. The ASS dropped to 2.50 in type I, 2.40 in type II, and 2.12 in type III at 1 month after treatment $(p=0.83)$. 
Table 1: High-resolution manometry findings in the three types of achalasia

\begin{tabular}{|c|c|c|c|c|c|}
\hline \multicolumn{2}{|c|}{ Type of achalasia } & \multirow{2}{*}{$\begin{array}{c}\text { LEP } \\
34.0523\end{array}$} & \multirow{2}{*}{$\begin{array}{c}\text { IRP } \\
15.4930\end{array}$} & \multirow{2}{*}{$\begin{array}{c}\text { DCI } \\
1441.17\end{array}$} & \multirow{2}{*}{$\begin{array}{c}\text { CFV } \\
51.3950\end{array}$} \\
\hline \multirow{5}{*}{1} & Mean & & & & \\
\hline & Number & 44 & 27 & 6 & 4 \\
\hline & Standard Deviation & 31.55570 & 7.40635 & 1626.324 & 92.44764 \\
\hline & Minimum & 6.00 & 2.00 & 354 & 2.10 \\
\hline & Maximum & 180.00 & 37.30 & 4000 & 190.00 \\
\hline \multirow{5}{*}{2} & Mean & 32.9985 & 20.8009 & 2149.31 & 52.2481 \\
\hline & Number & 196 & 101 & 29 & 21 \\
\hline & Standard Deviation & 17.90552 & 9.85443 & 1591.087 & 62.32795 \\
\hline & Minimum & 7.00 & 1.00 & 200 & 2.20 \\
\hline & Maximum & 157.00 & 67.00 & 6427 & 190.00 \\
\hline \multirow{5}{*}{3} & Mean & 37.4722 & 26.8571 & 1574.50 & 84.7500 \\
\hline & Number & 18 & 7 & 6 & 4 \\
\hline & Standard Deviation & 14.07199 & 12.44225 & 2453.496 & 52.44283 \\
\hline & Minimum & 16.00 & 15.00 & 100 & 9.00 \\
\hline & Maximum & 60.00 & 48.00 & 6525 & 130.00 \\
\hline \multirow{5}{*}{ Total } & Mean & 33.4903 & 20.0533 & 1961.56 & 56.6134 \\
\hline & Number & 258 & 135 & 41 & 29 \\
\hline & Standard Deviation & 20.59894 & 9.85266 & 1715.754 & 64.15987 \\
\hline & Minimum & 6.00 & 1.00 & 100 & 2.10 \\
\hline & Maximum & 180.00 & 67.00 & 6525 & 190.00 \\
\hline \multicolumn{2}{|c|}{$p$ value } & 0.666 & 0.007 & 0.559 & 0.656 \\
\hline
\end{tabular}

*LEP: lower esophageal pressure, IRP: integrated relaxation pressure, DCI: distal contractile integral, CFV: contractile front velocity

Table 2: Achalasia symptoms score between the three types of the disease 1 month after treatment and at the end of the follow-up

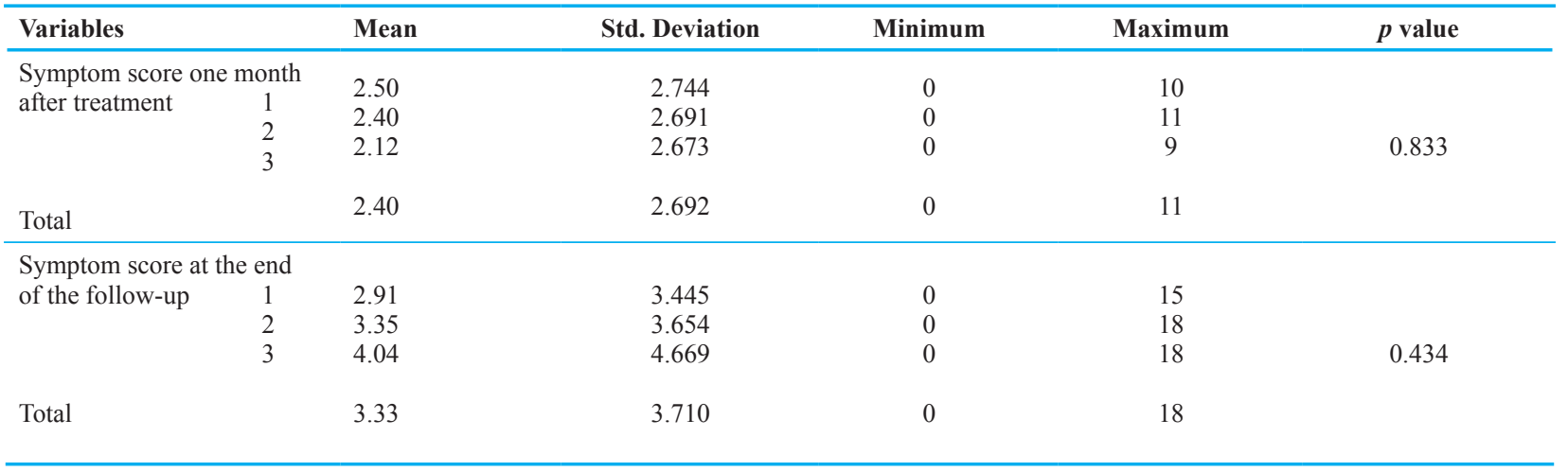

In TBE, the mean retained volume of barium at 5 th minute was reduced from $77.74,78.56$, and $45.46 \mathrm{~mL}$ before treatment to $10.08,17.44$, and 2.67 one month after treatment in type I, II, and III, respectively.

The mean height of barium decreased from 9.17, 10.09 , and $7.62 \mathrm{~cm}$ before treatment to $1.77,2.55$, and 1.05 $\mathrm{cm}$ a month after treatment in type I, II, and III, respectively (table 2).

\section{Secondary outcome}

The ASS values at the end of the study were 2.91, 3.35 , and 4.04 for types I, II and III, respectively ( $p=$ 0.43 , table 3 ). Overall, 492 balloon dilations were performed for the patients. In type I, 15/57 patients had two PBD, seven had three balloon dilations, and one had four PBDs done. For those with type II (223 patients), PBD was done 2, 3, 4, and 5 times in 73, 28, 4, and 1 patients. Finally, in type III (26 patients), PBD was performed in five patients twice and in two patients three times (table $4)$. There was no significant difference between the number of PBD sessions and the type of achalasia ( $p=$ 0.242 ). Combined therapy was done for 11,48 , and 4 patients in the three subtypes of achalasia $(p=0.205)$, and surgical myotomy was done after the failure of endoscopic therapy in 2,9 , and 2 patients in types I, II, and III, respectively $(p=0.204)$.

Eventually, at the end of the follow-up, 24 patients with type I (83\%), 82 patients with type II $(67 \%)$, and 
Table 3: Manometric and esophagogram findings of patients according to the three subtypes of achalasia

\begin{tabular}{lcccc}
\hline Variables & Type I $(\mathbf{n}=\mathbf{5 7})$ & Type II $(\mathbf{n}=\mathbf{2 2 3})$ & Type III $(\mathbf{n}=\mathbf{2 6})$ & $\boldsymbol{p}$ value \\
\hline Baseline mean LES pressure $(\mathrm{mmHg})$ & 34.0523 & 32.9985 & 37.4722 & 0.666 \\
\hline Baseline mean IRP $(\mathrm{mmHg})$ & 15.4930 & 20.8009 & 26.8571 & 0.007 \\
\hline Baseline DCI & 1441.17 & 2149.31 & 1574.50 & 0.559 \\
\hline Baseline CFV & 51.3950 & 52.2481 & 84.7500 & 0.656 \\
\hline Baseline ASS & 12.23 & 11.50 & 11.50 & 0.29 \\
\hline ASS-1 month & 2.50 & 2.40 & 2.12 & 0.833 \\
\hline ASS-EOF & 2.91 & 3.35 & 4.04 & 0.434 \\
\hline Baseline barium height $(\mathrm{cm})$ & 9.17 & 10.09 & 7.62 & 0.155 \\
\hline Barium height-1 month $\left(\mathrm{cm}^{2}\right.$ & 1.77 & 2.55 & 1.05 & 0.184 \\
\hline Baseline barium volume $\left(\mathrm{cm}^{3}\right)$ & 77.74 & 78.56 & 45.46 & 0.178 \\
\hline Barium volume-1 month $\left(\mathrm{cm}^{3}\right)$ & 10.08 & 17.44 & 2.67 & 0.128 \\
\hline$* *$ LS: live
\end{tabular}

**EES: lower esophageal sphincter, IRP: integrated relaxation pressure, DCI: distal contractile integral, CFV: contractile front velocity, ASS: achalasia symptom score, EOF: end of follow-up

Table 4: PBD sessions in each type of achalasia

\begin{tabular}{|c|c|c|c|c|c|c|c|c|}
\hline \multirow{2}{*}{ Variable } & & \multicolumn{5}{|c|}{ PBD count } & \multirow{2}{*}{ Total } & \multirow{2}{*}{ Mean } \\
\hline & & 1 & 2 & 3 & 4 & 5 & & \\
\hline \multirow{3}{*}{ Type of achalasia } & 1 & 34 & 15 & 7 & 1 & 0 & 57 & 1.56 \\
\hline & 2 & 117 & 73 & 28 & 4 & 1 & 223 & 1.65 \\
\hline & 3 & 19 & 5 & 2 & 0 & 0 & 26 & 1.34 \\
\hline Total & & 170 & 93 & 37 & 5 & 1 & 306 & $p=0.242$ \\
\hline
\end{tabular}

5 patients with type III $(83 \%)$ showed sustained good responses $(p=0.528)$.

Our results showed no significant difference between the three subgroups in response to PBD.

\section{DISCUSSION}

Achalasia is divided into three subtypes based on HRM results using the Chicago classification. Different success rates for the three manometric subtypes of achalasia have been reported, suggesting that the manometric classification may help determine the treatment of choice.

We conducted a study to determine the differences in long-term treatment response between these three subtypes. Our results did not reveal any significant difference between the three subgroups of achalasia in their long-term response to treatment, although the short-term response was better in types I and II. Earlier relapses were seen in type III compared with types I and II.

Also, no significant difference was seen between the three subtypes in terms of manometric criteria except for the LES residual pressure that was significantly higher in type III than type I.
In one study, the frequency of each subtype was $47 \%$ for type I and II, and 5\% type for III. ${ }^{21}$ In another study, among 99 patients with achalasia, 21 had type I (21.2\%), 49 had type II (49.5\%), and 29 had type III (29.3\%). ${ }^{19}$ In our study, the frequency of subtypes was 29 as type I (20\%), 99 as type II (67\%), and 20 as type III (14\%).

In a similar study, Rohof and colleagues concluded that the efficacy of treatment, mainly consisting of PBD, strongly varies depending on the manometric type. Success rates were indeed significantly higher for type II achalasia (96\%) compared with type I (56\%), and type III $(29 \%) .{ }^{18}$ In another study, Pandolfino reported that patients with type II of the disease were significantly more likely to respond to any treatment (Botox [71\%], pneumatic dilation [91\%], or Heller myotomy [100\%]) than patients with type I ( $56 \%$ overall), or type III $(29 \%$ overall) of the disease..$^{19}$ In another study in India, type II achalasia showed the best response to pneumatic dilatation. ${ }^{20}$ However, in our study, these differences were not significant.

Achalasia is one of the most studied esophageal motility disorders caused by impaired LES relaxation with esophageal aperistalsis. Achalasia can be categorized 
into three subtypes, of which type II is the most common.

In this study, we compared individual symptom scores during the long-term follow-up period, and no significant differences were seen in LES resting pressure and ASS before treatment, as well as response to treatment between the three subtypes.

Previous studies have shown a better response to treatment in type II. Our study revealed no significant difference in the three different subtypes of achalasia in a long-term follow-up. No difference was observed between the three subtypes with respect to the height and volume of barium in TBE and the ASS after treatment.

In this study, we have shown that the manometric subtype of patients with achalasia does not have an important role in clinical success in the long term, and there was no significant difference regarding the need for combined therapy and surgical myotomy between the three subtypes. Still, one of the limitations of our study was the low incidence of type III achalasia. The incidence is low in the population, so additional studies focusing on type III achalasia need to be performed in multicenter studies to provide sufficient cases.

The strength of our study was the prospective design and the large number of patients who were followed up in the long term.

We conclude that in all subtypes, even though there is no definite cure, with current treatment modalities, palliation of symptoms is possible in over $90 \%$ of patients. So, clinical success is not determined by the subtype in the long term.

\section{ETHICAL APPROVAL}

There is nothing to be declared.

\section{CONFLICT OF INTEREST}

The authors have none to declare.

\section{REFERENCES}

1. Hirano I. Pathophysiology of achalasia. Curr Gastroenterol Rep 1999;1:198-202. doi: 10.1007/s11894-999. 0034-2.

2. Goldblum JR, Rice TW, Richter JE. Histopathologic features in esophagomyotomy specimens from patients with achalasia. Gastroenterology 1996;111:648-54. doi: 10.1053/gast.1996.v111.pm8780569.

3. Mearin F, Mourelle M, Guarner F, Salas A, Riveros-
Moreno V, Moncada S, et al. Patients with achalasia lack nitric oxide synthase in the gastro-oesophageal junction. Eur J Clin Invest 1993;23:724-8. doi: 10.1111/j.13652362.1993.tb01292.x.

4. Kwiatek MA, Post J, Pandolfino JE, Kahrilas PJ. Transient lower oesophageal sphincter relaxation in achalasia: everything but LOS relaxation. Neurogastroenterol Motil 2009;21:1294-e123. doi: 10.1111/j.13652982.2009.01338.x.

5. Spechler SJ, Castell DO. Classification of oesophageal motility abnormalities. Gut 2001;49:145-51. doi: 10.1136/gut.49.1.145.

6. Pandolfino JE, Kahrilas PJ. AGA technical review on the clinical use of esophageal manometry. Gastroenterology 2005;128:209-24. doi: 10.1053/j.gastro.2004.11.008.

7. Mikaeli J, Islami F, Malekzadeh R. Achalasia: a review of Western and Iranian experiences. World J Gastroenterol 2009;15:5000-9. doi: 10.3748/wjg.15.5000.

8. Farrokhi F, Vaezi MF. Idiopathic (primary) achalasia. Orphanet J Rare Dis 2007;2:38. doi: 10.1186/1750-1172-2-38.

9. Todorczuk JR, Aliperti G, Staiano A, Clouse RE. Reevaluation of manometric criteria for vigorous achalasia. Is this a distinct clinical disorder? Dig Dis Sci 1991;36:2748. doi: 10.1007/BF01318195.

10. Sanderson DR, Ellis FH, Schlegel JF, Olsen AM. Syndrome of vigorous achalasia: Clinical and physiologic observations. Dis Chest 1967;52:508-17. doi: 10.1378/ chest.52.4.508.

11. Bondi JL, Godwin DH, Garrett JM. "Vigorous" achalasia. Its clinical interpretation and significance. Am J Gastroenterol 1972;58:145-55.

12. Camacho-Lobato L, Katz PO, Eveland J, Vela M, Castell DO. Vigorous achalasia: original description requires minor change. J Clin Gastroenterol 2001;33:375-7. doi: 10.1097/00004836-200111000-00006.

13. Jung KW, Jung HY, Yoon IJ, Kim do H, Park HW, Chung JW, et al. Basal and residual lower esophageal pressures increase in old age in classic achalasia, but not vigorous achalasia. J Gastroenterol Hepatol 2010;25:1452-5. doi: 10.1111/j.1440-1746.2010.06298.x.

14. Goldenberg SP, Burrell M, Fette GG, Vos C, Traube M. Classic and vigorous achalasia: a comparison of manometric, radiographic, and clinical findings. Gastroenterology 1991;101:743-8. doi: 10.1016/0016-5085(91)90534-r.

15. Fox M, Hebbard G, Janiak P, Brasseur JG, Ghosh S, Thumshirn M, et al. High-resolution manometry predicts the success of oesophageal bolus transport and identifies clinically important abnormalities not detected by conventional manometry. Neurogastroenterol Motil 2004;16:533-42. doi: 10.1111/j.1365-2982.2004.00539.x.

16. Pandolfino JE, Ghosh SK, Rice J, Clarke JO, Kwiatek MA, Kahrilas PJ. Classifying esophageal motility by pressure topography characteristics: a study of 400 patients and 75 controls. Am J Gastroenterol 2008;103:27-37. 
doi: 10.1111/j.1572-0241.2007.01532.x.

17. Roman S, Kahrilas PJ, Boris L, Bidari K, Luger D, Pandolfino JE. High-resolution manometry studies are frequently imperfect but usually still interpretable. Clin Gastroenterol Hepatol 2011;9:1050-5.

18. Rohof WO, Salvador R, Annese V, Bruley des Varannes $\mathrm{S}$, Chaussade S, Costantini M, et al. Outcomes of treatment for achalasia depend on manometric subtype. Gastroenterology 2013;144:718-25; quiz e13-4. doi: 10.1053/j.gastro.2012.12.027.

19. Pandolfino JE, Kwiatek MA, Nealis T, Bulsiewicz W, Post J, Kahrilas PJ. Achalasia: a new clinically relevant classification by high-resolution manometry. Gastroenterology 2008;135:1526-33. doi: 10.1053/j.gastro.2008.07.022.

20. Rhee K, Jeon H, Kim JH, Yoon YH, Park H, Lee SI. An evidence of esophageal decompensation in patients with achalasia in the view of its subtype: a retrospective study. J Neurogastroenterol Motil 2013;19:319-23. doi: 10.5056/jnm.2013.19.3.319.

21. Pratap N, Kalapala R, Darisetty S, Joshi N, Ramchandani $\mathrm{M}$, Banerjee R, et al. Achalasia cardia subtyping by highresolution manometry predicts the therapeutic outcome of pneumatic balloon dilatation. $J$ Neurogastroenterol Motil 2011;17:48-53. doi: 10.5056/jnm.2011.17.1.48.

22. Kahrilus PJ, Katzka D, Richtar JE. Clinical Practice Update: The use of Per-Oral Endoscopic Myotomy in Achalasia: Expert Review and Best Practice Advise From the A.G.A. Institute. Gastroenterology 2017;153:120511. doi: $10.1053 /$ j.gastro.2017.10.001.

23. Torresan F, Ioannou A, Azzaroli F, Bazzoli F. Treatment of achalasia in the era of high-resolution manometry. Ann Gastroenterol 2015;28:301-8.

24. Pandolfino JE, Ghosh SK, Zhang Q, Jarosz A, Shah N, Kahrilas PJ. Quantifying EGJ morphology and relaxation with high-resolution manometry: a study of 75 asymptomatic volunteers. Am J physiology Gastrointest Liver Physiol 2006;290:G1033-40. doi: 10.1152/ajpgi.00444.2005.

25. Ghosh SK, Pandolfino JE, Rice J, Clarke JO, Kwiatek M, Kahrilas PJ. Impaired deglutitive EGJ relaxation in clinical esophageal manometry: a quantitative analysis of 400 patients and 75 controls. Am J Physiology Gastrointest Liver Physiol 2007;293:G878-85. doi: 10.1152/ ajpgi.00252.2007.

26. Pandolfino JE, Fox MR, Bredenoord AJ, Kahrilas PJ. High-resolution manometry in clinical practice: utilizing pressure topography to classify oesophageal motility abnormalities. Neurogastroenterol Motil 2009;21:796-806. doi: 10.1111/j.1365-2982.2009.01311.x.

27. Mikaeli J, Veisari AK, Fazlollahi N, Mehrabi N, Soleimani HA, Shirani S, et al. Ethanolamine oleate versus botulinum toxin in the treatment of idiopathic achalasia. Ann Gastroenterol 2015;28:229-35.

28. Niknam R, Mikaeli J, Fazlollahi N, Mahmoudi L, Mehrabi N, Shirani S, et al. Ethanolamine oleate as a novel therapy is effective in resistant idiopathic achalasia. Dis Esophagus
2014;27:611-6. doi: 10.1111/dote.12122.

29. Montazeri G, Nouri N, Estakhri A, Shirani S, Derakhshan $\mathrm{MH}$, Yaghoobi M, et al. Lower oesophageal sphincter pressure and timed barium oesophagogram: two objective parameters in the non-invasive assessment of primary achalasia. Aliment Pharmacol Ther 2005;22:261-5. doi: 10.1111/j.1365-2036.2005.02557.x. 